\title{
Direct Contact Transmission Infection
}

National Cancer Institute

\section{Source}

National Cancer Institute. Direct Contact Transmission Infection. NCI Thesaurus. Code C50534.

Infection produced by direct contact with another person. 